\title{
An Efficient, Practical, and Selective Multicomponent Copper-Catalyzed Process
}

Metal-Mediated

Synthesis

\section{Key words}

\section{boron}

multicomponent reaction

copper

\section{SYNFACTrith}

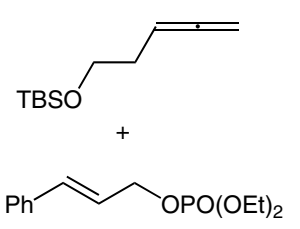

Selected examples:

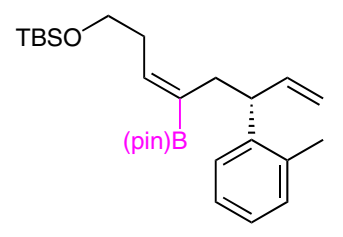

$72 \%$ yield $>98 \%$ branched $>98 \%$ Z, er $>99: 1$

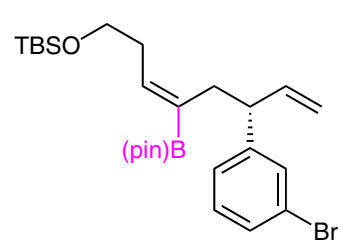

$68 \%$ yield $>98 \%$ branched $>98 \%$ Z, er $=94: 6$<smiles>[B]/C(=C/CCOC(C)(C)C)C[C@H](C=C)c1ccc(Cl)cc1</smiles>

$75 \%$ yield $>98 \%$ branched $>98 \% Z$, er $=92: 8$

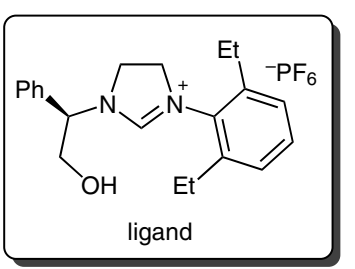<smiles>C=C[C@H](CCc1ccccc1)C/C([18OH])=C\CCOC(C)(C)C</smiles>

$84 \%$ yield $>98 \%$ branched $>98 \%$ Z, er $=94: 6$<smiles>C=C[C@H](C/C([B]O)=C\C/C=C/c1ccccc1)c1ccccc1</smiles><smiles>C=C[C@@H](C/C([10BH]c1ccccc1)=C\CCC#C[SiH2]C(C)(C)C)c1ccccc1</smiles><smiles>C=C[C@@H](C/C([Pb])=C\CCNC(=O)c1ccccc1)c1ccccc1</smiles><smiles>C=C[C@H](C/C(=C\CCC(=O)N(C)OC)[PH2]c1ccccc1)Cc1ccccc1</smiles>

$77 \%$ yield $>98 \%$ branched $>98 \%$ Z, er > 99:1

$73 \%$ yield $>98 \%$ branched $>98 \%$ Z, er $=99: 1$
Significance: The authors demonstrate the generation of multifunctional alkenylboron fragments starting from two simple unsaturated organic molecules and a commercially available diboron reagent. These fragments were shown to carry several advantageous properties. The catalyst used is generated in situ by the reaction of inexpensive $\mathrm{CuCl}$ with a chiral ligand which was prepared on multigram scale in good yield.
Comment: The practical protocol can be performed on large scale and makes gram quantities of a variety of complex organic molecules easily available. The products, which contain a stereogenic carbon center, a monosubstituted alkene, and an easily functionalizable Z-trisubstituted alkenylboron group, are obtained in good yields and excellent selectivities.

SYNFACTS Contributors: Paul Knochel, Thomas Klatt

Dol: 10.1055/s-0034-1379656; Reg-No.: P16014SF 